\title{
IMPLEMENTASI PROGRAM ADMINISTRASI PEMBAYARAN BERBASIS DEKSTOP (STUDI KASUS: SMA NEGERI 1 CIKAMPEK)
}

\author{
Surtika Ayumida ${ }^{1 *}$ - Mohammad Syamsul Azis ${ }^{2}$, Zulfirman Gherar Fiano ${ }^{3}$ \\ ${ }^{1,3}$ Universitas Bina Sarana Informatika, ${ }^{2}$ STMIK Nusa Mandiri Jakarta \\ ${ }^{1}$ Email: surtika.skm@bsi.ac.id \\ 2Email:mohammad.myz@nusamandiri .ac.id \\ ${ }^{3}$ Email: zulfirman098@bsi.ac.id
}

\begin{abstract}
In this era of globalization, the application of administrative data processing has been used by many parties, both agencies, organizations, as well as in educational institutions that will trigger the performance of agencies to be better than before. The payment data processing of SPP on SMA Negeri 1 Cikampek until now are still operating manually, so that activities associated with the administration is still slow even still queued to make payments. Specifically the functions performed by the application payment administration developed include, student data collection, alumni data, SPP Payment, and collection payment. Display student information, alumni information, payment SPP reports, until collection reports. This application payment administration is developed using Java programming language. With this computerized payment sistem hopely to improve the data processing of SPP payment, bimbingan study, study tour, and others effectively and efficiently.
\end{abstract}

Keywords : Program Design, Program Application School Administration 


\section{PENDAHULUAN}

\section{Latar Belakang}

Kebutuhan masyarakat akan teknologi informasi semakin besar, sehingga dibutuhkan media informasi yang cepat, tepat dan akurat dalam upaya memenuhi kebutuhan akan informasi tersebut. Teknologi-teknologi baru dibidang telekomunikasi dan jaringan komputer terus bermunculan dengan konsepkonsep baru. Menurut Arifin [1] komputer adalah "peralatan elektronika yang menerima masukan data, mengolah data dan memberikan hasil keluaran dalam bentuk informasi baik berupa teks, gambar, suara, maupun video."

Dalam upaya peningkatan mutu Sumber Daya Manusia (SDM) dan proses kelancaran dari administrasi sekolah khususnya sistem pembayaran SPP (Sumbangan Penyelenggaraan Pendidikan) yang membutuhkan kecepatan dan ketepatan agar pelayanan terhadap masyarakat khususnya wali siswa dan siswa itu sendiri dapat dilayani dengan professional.

Sistem pembayaran yang beijalan pada SMA Negeri 1 Cikampek masih secara manual dicatat pada buku lalu data dari buku itu disalin kedalam komputer menggunakan excel sehingga timbul suatu permasalahan dalam hal keefektifan pembuatan laporan dan efisiensi pengelolaan data menjadi sebuah informasi dalam proses manajemen sekolah. Dalam lingkungan pendidikan, pemanfaatan teknologi informasi sangat penting, dan harus dapat digunakan untuk berbagai keperluan.

Dari masalah di atas, peneliti berniat untuk mengembangkan sebuah sistem informasi berbasis desktop yang diharapkan dapat membantu pengelolaan data pembayaran SPP menjadi lebih baik. Dengan adanya sistem informasi ini diharapkan dapat membantu aktifitas sekolah terutama di bagian bendahara dalam mengetahui pembayaran SPP dan juga pembayaran lainnya agar menyajikannya ke dalam bentuk laporan. Untuk itu maka diberlakukan suatu program yang terkomputerisasi dalam rangka memberikan informasi kepada pihak yang bersangkutan secara cepat, tepat, dan akurat.

\section{TINJAUAN PUSTAKA Administrasi}

Menurut M. Rahman [2] Administrasi adalah "segenap proses penyelenggaraan dalam setiap usaha kerjasama sekelompok manusia untuk mencapai tujuan tertentu". Pengertian proses tersebut adalah rangkaian perbuatan manusia yang mengandung maksud tertentu yang memang dikehendaki oleh yang melakukan perbuatan itu.

\section{Pengertian Program}

Program Menurut Utami dan Sukrisno [3] memberikan pengertian bahwa "Program adalah urutan instruksi untuk menjalankan suatu komputasi. Komputasi dapat berupa perhitungan matematis, seperti pengecekan bilangan prima, pencarian akar-akar persamaan kuadrat, atau yang lainnya. Namun juga dapat berupa pencarian dan penggantian text dalam dokumen".

\section{ERD}

Menurut Rosa, A. S. dan M. Salahuddin [4] mendefinisikan bahwa "Entity Relationship Diagram (ERD) adalah pemodelan awal basis data yang dikembangkan berdasarkan teori himpunan dalam bidang matematika yang digunakan untuk pemodelan basis data relational".

\section{Basis Data}

Menurut R. Yanto [5], Basis data merupakan "kumpulan data yang saling berhubungan yang disimpan secara bersama sedemikian rupa dan tanpa pengulangan (redudansi), untuk memenuhi berbagai kebutuhan".

\section{Pengertian Flowchart}

Menurut Barakbah [6] "Flowchart merupakan gambar atau bagan yang memperlihatkan urutan atau langkah-langkah dari suatu program dan hubungan antar proses beserta pernyataannya, gambaran ini dinyatakan dengan simbol".

\section{Pengkodean}

Menurut Ariansa dalam [7], "Pengkodean (Encoding) adalah proses perubahan karakter data yang akan dikirim dari suatu titik ke titik lain dengan kode yang dikenal oleh setiap terminal yang ada, dan menjadikan setiap karakter data dalam sebuah informasi digital ke 
dalam bentuk biner agar dapat ditransmisikan. c. Pembuatan kode program

Suatu terminal yang berbeda menggunakan kode biner yang berbeda untuk mewakili setiap karakter".

\section{METODE PENELITIAN}

\section{Teknik Pengumpulan Data}

Teknik pengumpulan data yang digunakan oleh peneliti dalam melakukan pengumpulan data adalah[8]:

a. Observasi

Peneliti melakukan observasi secara langsung ke SMA Negeri 1 Cikampek untuk mengamati proses pencatatan pembayaran SPP, proses pencatatan pembayaran daftar ulang, study tour, dan bimbingan belajar, serta proses pembuatan laporan pembayaran SPP dan lain - lain pada SMA Negeri 1 Cikampek.

b. Wawancara

Metode ini adalah pengumpulan data melalui tanya jawab yang dilakukan peneliti kepada bagian bendahara SMA Negeri 1 Cikampek yaitu Bapak Sugiono secara langsung.

c. Studi Pustaka

Dengan terbatasnya ilmu yang peneliti miliki, maka dalam penelitian ini peneliti ditunjang dengan berbagai literatur seperti buku-buku tentang basis data, pemrograman java netbeans, rekayasa perangkat lunak, jurnal tentang pemrograman, dan bahasa pemrograman.

\section{Metode Pengembangan Perangkat Lunak}

Metode yang digunakan pada pengembangan perangkat lunak ini menggunakan model waterfall. urut mulai dari level kebutuhan sistem lalu menuju ke tahap analisis, desain, coding, testing/verification, dan maintenance.

a. Desain

Dalam tahap desain hal yang dilakukan peneliti untuk membuat program yang akan dibuat adalah merancang basis data terlebih dahulu kemudian dilanjutkan dengan membuat entity relationship diagram, logical record structure, flow chart, Hierarchy Input Process Output dan pembuatan desain user interface program tersebut.
Setelah menyelesaikan tahap desain, peneliti melanjutkan kedalam tahap pengkodean program menggunakan bahasa pemrograman Java, database MySQL, dan menggunakan tools Netbeans IDE 8.2.

d. Pengujian

Setelah program telah selesai dibuat, tahap pengujian ini adalah tahap yang paling penting dimana peneliti harus melakukan pengecekan apakah ada error saat melakukan penginputan data kedalam program, bug yang tidak terdeteksi sebelumnya, dan juga pengecekan feedback dari program ke user apakah sesuai yang diinginkan atau tidak.

e. Pendukung (support) atau pemeliharaan (maintenance)

Tidak menutup kemungkinan sebuah perangkat lunak mengalami perubahan ketika sudah dikirimkan ke user. Perubahan bisa terjadi karena adanya kesalahan yang muncul dan tidak terdeteksi saat pengujian atau perangkat lunak harus beradaptasi dengan lingkungan baru.

Dalam tahap ini peneliti harus selalu melakukan pemeliharaan kepada program dari mulai backup/restore database, penambahan fitur, dan lain- lain.

\section{HASIL PENELITIAN DAN PEMBAHASAN}

\section{Analisa Kebutuhan Pengguna}

Dalam program ini kebutuhan pengguna menggunakan dua hak akses yaitu bendahara dan kepala sekolah, bendahara yang melakukan 
segala transaksi dan kepala sekolah hanya 4. Spesifikasi File melihat laporan saja.

a. Kebutuhan Pengguna Bendahara Bendahara dapat mengakses hampir keseluruhan fitur program, dari mulai menambahkan siswa, membuat tagihan, jenis pembayaran, dan pembayaran SPP, kecuali data user, dan pengaturan program.

b. Kebutuhan Pengguna Kepala Sekolah Untuk hak akses kepala sekolah, kepala sekolah dapat mengakses hanya dibagian laporan data user dan pengaturan.

2. Entity Relationship Diagram

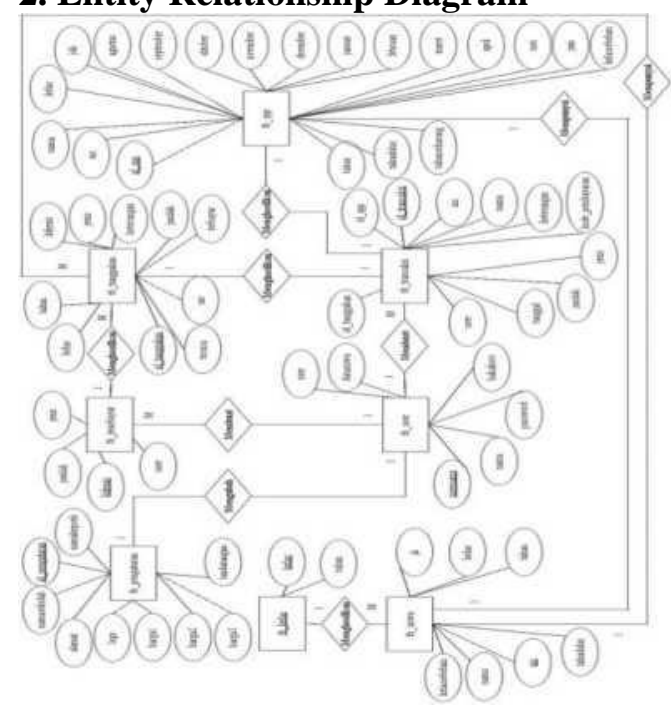

Gambar 1. Entity Relationship Diagram

\section{Logical Record Structure}

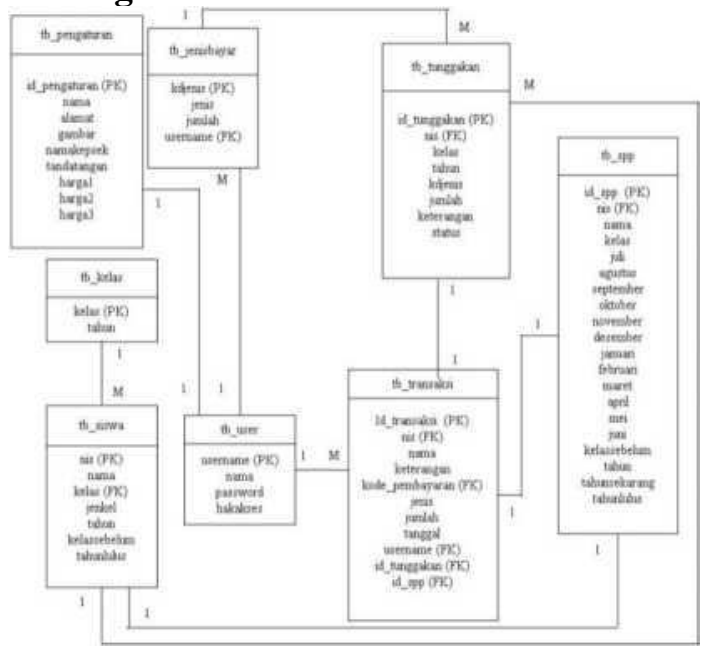

Gambar 2. Logical Record Structure
Tabel 3. Spesilikasi File Pengaturan

\begin{tabular}{|c|l|c|c|c|l|}
\hline a No & Elemen Data & Akronim & Tipe & Panjang & Keterangan \\
\hline 1. & Id Pengaturan & id_pengaturan & int & 8 & Primary Key \\
\hline 2. & Nama sekolah & Namasekolah & varchar & 30 & \\
\hline 3. & Alamat & Alamat & text & 8 & \\
\hline 4. & Gambar & Gambar & longblob & 8 & \\
\hline 5. & $\begin{array}{c}\text { Nama kepala } \\
\text { Sekolah }\end{array}$ & Namakepsek & varchar & 30 & \\
\hline 6. & Tanda tangan & Tandatangan & longblob & 8 & \\
\hline 7. & Jumlali SPP 1 & hargal & int & 8 & \\
\hline 8. & Jumlah SPP 2 & harga2 & int & 8 & \\
\hline 9. & Jumlali SPP 3 & harga3 & int & 8 & \\
\hline 7 & \multicolumn{7}{|l|}{ Tahun Lulus } & Tahunlulus & int & 4 & \\
\hline 7. &
\end{tabular}

b. Spesifikasi File User Tabel 2. $\underline{\text { Spesifikasi File User }}$

\begin{tabular}{|c|c|l|c|c|l|}
\hline No & Elemen Data & Akronim & Tipe & Panjang & Keterangan \\
\hline i. & Username & Username & varchar & 15 & $\begin{array}{l}\text { Primary } \\
\text { Kov }\end{array}$ \\
\hline 2. & Nama & Nama & varchar & 30 & \\
\hline 3. & Password & Password & varchar & 30 & \\
\hline 4. & Hak Akses & Hakakses & varchar & 15 & \\
\hline
\end{tabular}

c. Spesifikasi File Pengaturan

d. Spesifikasi File SPP Tabel 4. Spesifikasi File SPP

\begin{tabular}{|c|c|c|c|c|l|}
\hline No & Elemen Data & Akronim & Tipe & Panjang & Keterangan \\
\hline 1. & Id SPP & id_spp & int & 8 & Primary Key \\
\hline 2. & NIS & Nis & varchar & 9 & Foreign Key \\
\hline 3. & Nama & Nama & varchar & 30 & \\
\hline 4. & Kelas & Kelas & varchar & 10 & \\
\hline 5. & Juli & Juli & int & 8 & \\
\hline 6. & Agustus & Agustus & int & 8 & \\
\hline 7. & September & September & int & 8 & \\
\hline 8. & Oktober & Oktober & int & 8 & \\
\hline 9. & November & November & int & 8 & \\
\hline 10. & Desember & Desember & int & 8 & \\
\hline 11. & Januari & Januari & int & 8 & \\
\hline 12. & Febmari & Febmari & int & 8 & \\
\hline 13. & Maret & Maret & int & 8 & \\
\hline 14. & April & April & int & 8 & \\
\hline 15. & Mei & Mei & int & 8 & \\
\hline 16. & Juni & Juni & int & 8 & \\
\hline 17. & Kelas Sebelum & Kelassebelum & varchar & 10 & \\
\hline 18. & Tahun & Tahun & varchar & 1 & \\
\hline 19. & Tahun Sekarang & tahun sekarang & varchar & 1 & \\
\hline 20. & Tahun Lulus & Tahunlulus & varchar & 4 & \\
\hline
\end{tabular}


e. Spesifikasi File Jenis Bayaran

Tabel 5. Spesifikasi File Jenis Bayaran
\begin{tabular}{|c|c|c|c|c|l|}
\hline No & Elemen Data & Akronim & Tipe & Panjang & Keterangan \\
\hline 1. & Kode Bayaran & Kode_bayarail & varchar & 8 & Primary Key \\
\hline 2. & Jenis & Jenis & varchar & 20 & \\
\hline 3. & Jurnlah & Jumlah & int & 8 & \\
\hline 4. & Username & Username & varchar & 15 & Foreign Key \\
\hline
\end{tabular}

\section{f. Spesifikasi File Tunggakan}

Tabel 6. Spesifikasi File Tunggakan

\begin{tabular}{|c|c|c|c|c|l|}
\hline No & Elemen Data & Akronim & Tipe & Panjang & Keterangan \\
\hline 1. & Id Tunggakan & idtunggakan & int & 8 & Primary Key \\
\hline 2. & NIS & Nis & varchar & 20 & Foreign Key \\
\hline 3. & Kelas & Kelas & varchar & 15 & \\
\hline 4. & Tahun & Tahun & varchar & 1 & \\
\hline 5. & Kode Jenis & Kdjenis & varchar & 8 & \\
\hline 6. & Jenis & Jenis & varchar & 20 & \\
\hline 7. & Jumlah & Jumlah & double & 8 & \\
\hline 8. & Keterangan & Keterangan & text & 50 & \\
\hline 9. & Status & Status & double & 8 & \\
\hline 10. & Tersisa & Tersisa & double & 8 & \\
\hline
\end{tabular}

\section{g. Spesifikasi File Transaksi}

Tabel 7. Spesifikasi File Transaksi

\begin{tabular}{|c|c|c|c|c|c|}
\hline $\mathrm{N}_{0}$ & Elemen Data & Akronim & Tipe & Panjang & Keterangan \\
\hline 1. & Id Transaksi & Idjansaksi & int & 8 & $\begin{array}{c}\text { Primaiy } \\
\text { Key }\end{array}$ \\
\hline 2. & NIS & Nis & varchar & 9 & Foreign Key \\
\hline 3. & Nama & Naina & Varchar & 30 & \\
\hline 4. & Keterangan & Keterangan & text & 8 & \\
\hline 5. & $\begin{array}{r}\text { Kode } \\
\text { Pembayaian }\end{array}$ & Kodejembayaran & varchar & 14 & \\
\hline 6. & Jenis & Jenis & Varchar & 20 & \\
\hline 7. & Jumlah & Jumlah & int & 8 & \\
\hline 8. & Tanggal & Tanggal & date & 8 & \\
\hline 9. & Id Tungrgakan & Idtunggakan & int & 8 & Foreign Key \\
\hline 10. & Id SPP & Idspp & int & 8 & Foreign Key \\
\hline
\end{tabular}

\section{h. Spesifikasi File Kelas}

Tabel 8. Spesifikasi File Kelas

\begin{tabular}{|c|c|c|c|c|l|}
\hline No & Elemen Data & Akronim & Tipe & Panjang & Keterangan \\
\hline 1. & Naina Kelas & Kelas & varchar & 10 & PrinmKer \\
\hline 2. & Tahun & Tatnin & varchar & 1 & \\
\hline
\end{tabular}

\section{HIPO}

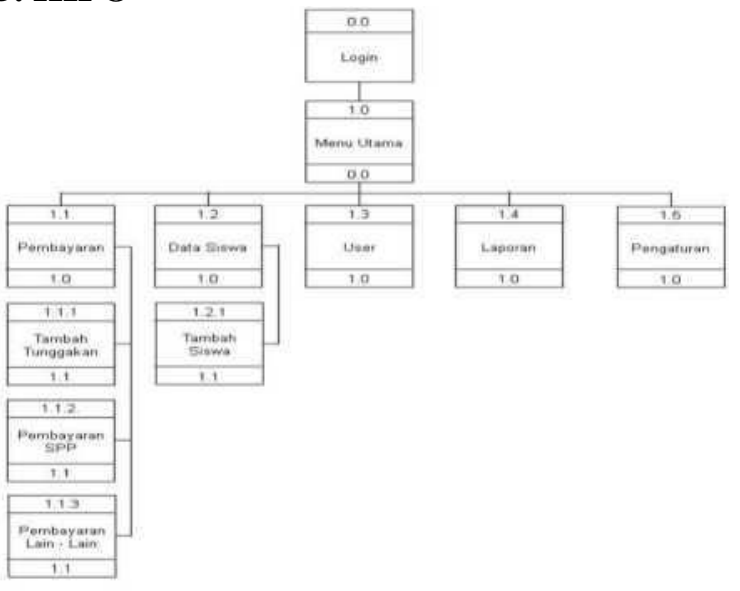

Gambar 3. HIPO

\section{Flowchart}

a. Flowchart Login

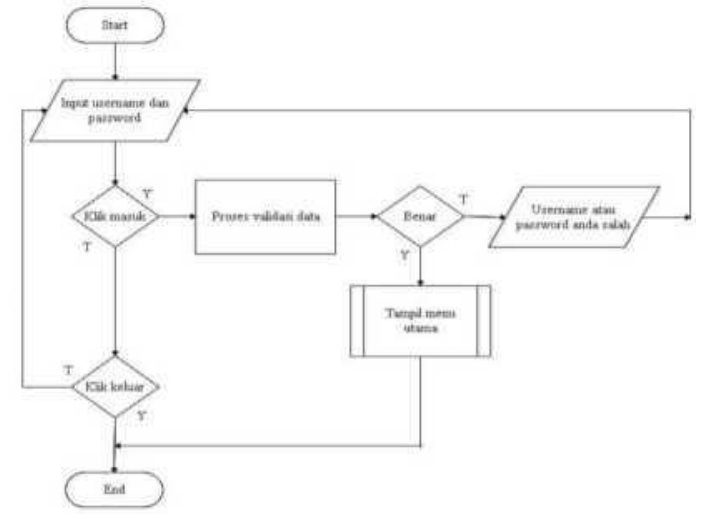

Gambar 4. Flowchart Login b. Flowchart Data Siswa

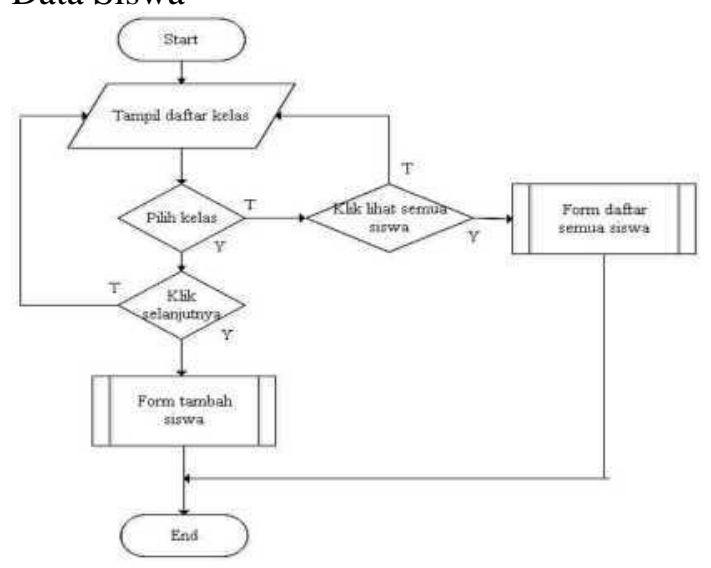

Gambar 5. Flowchart Data Siswa 
c. Flowchart Pengaturan

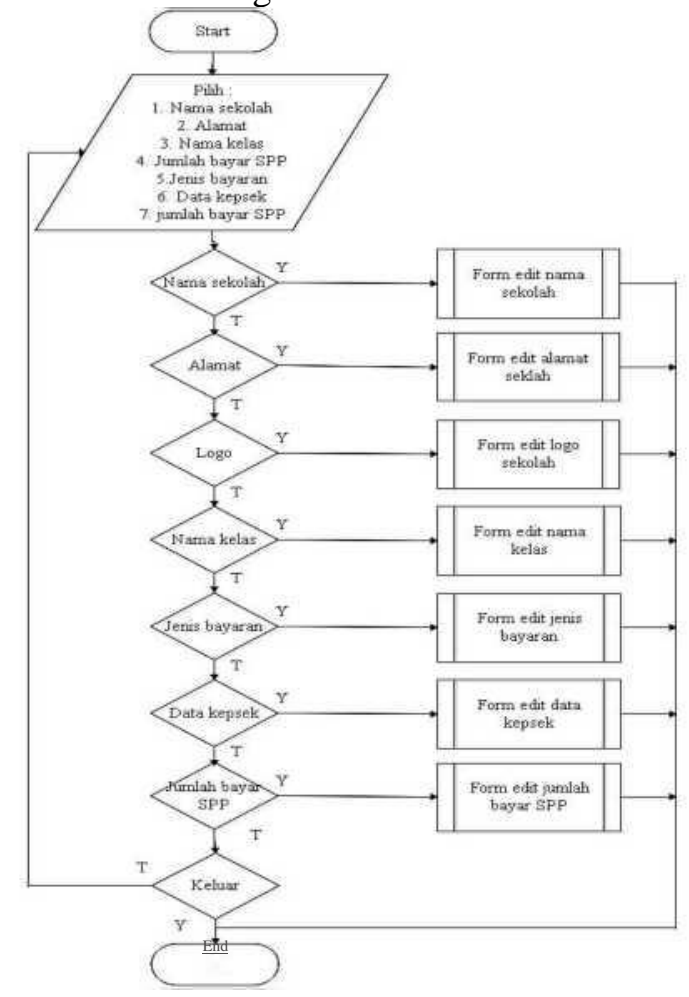

Gambar 6. Flowchart Pengaturan d.

Flowchart Tambah User

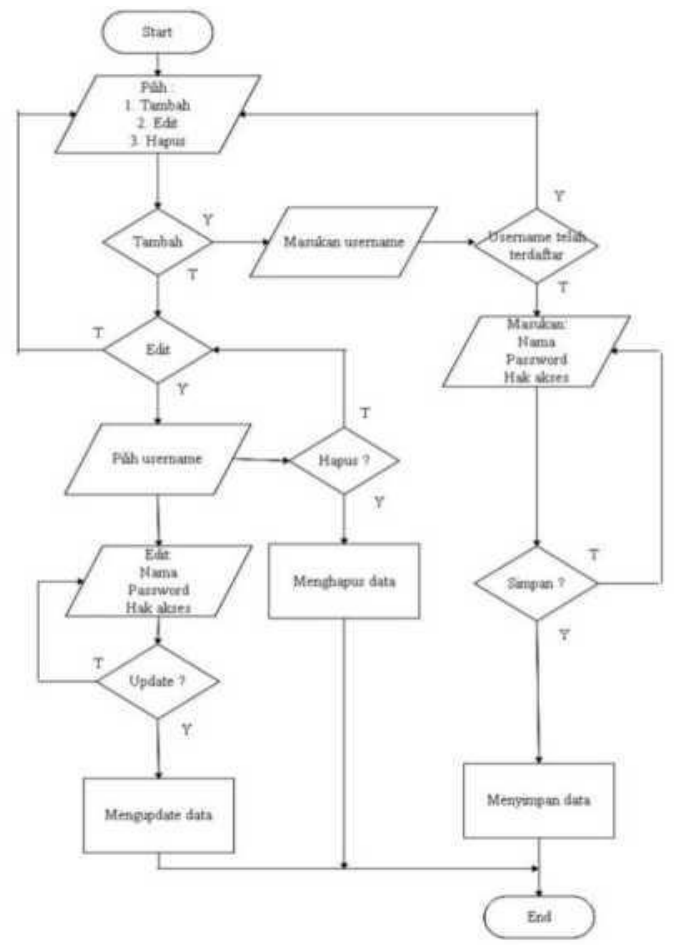

Gambar 7. Flowchart Tambah User e. Flowchart Tambah Siswa

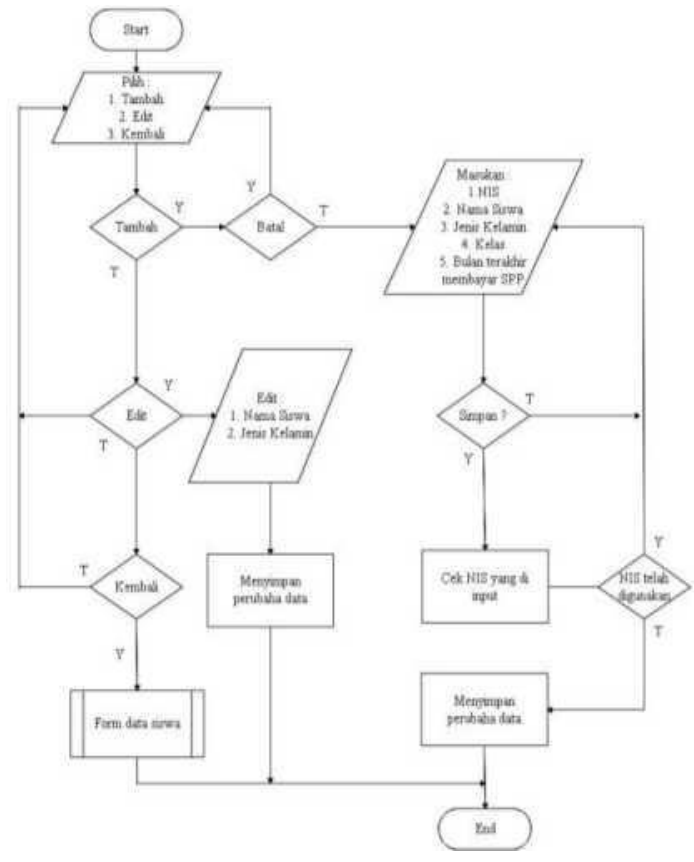

Gambar 8. Flowchart Tambah Siswa f.

Flowchart Naik Kelas

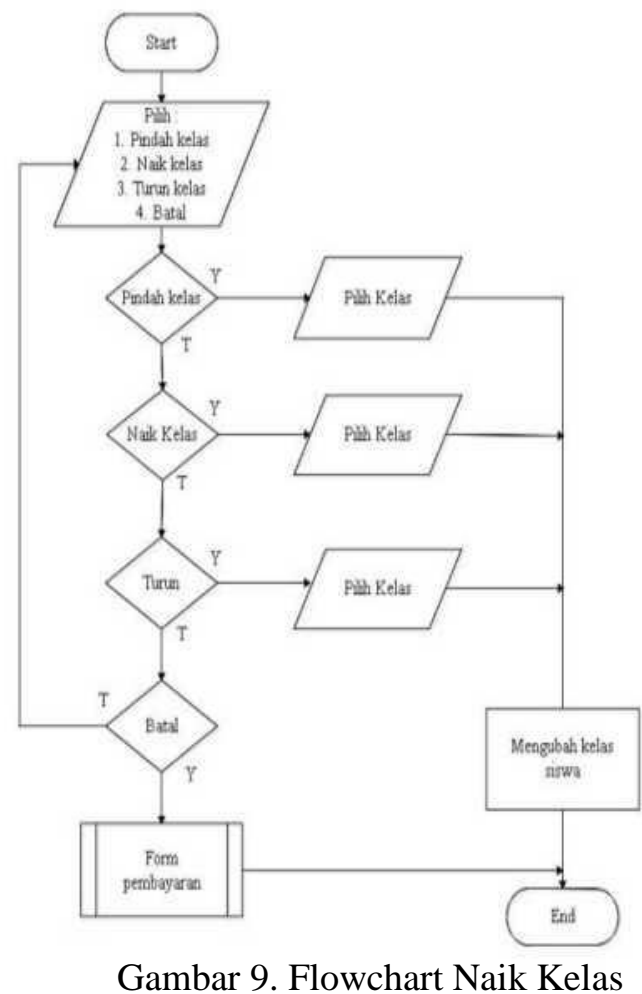

g. Flowchart Tambah Tunggakan 


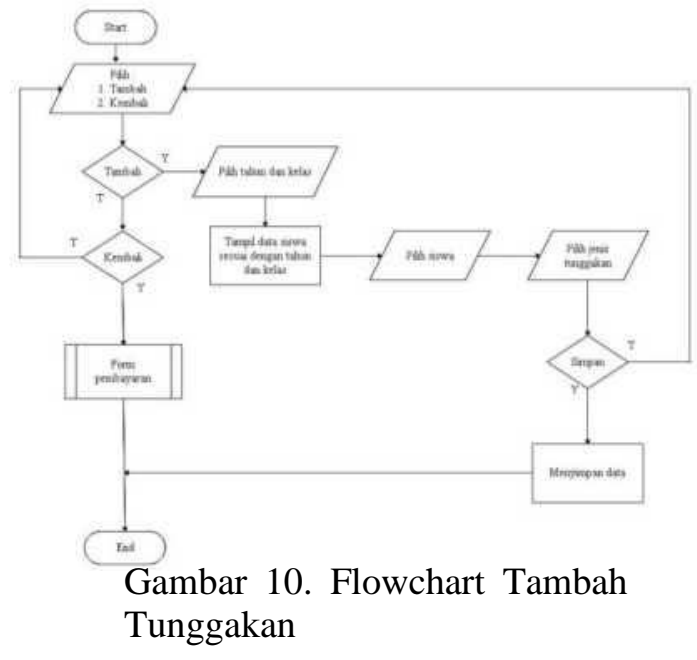

h. Flowchart Tambah Pembayaran Lainnya

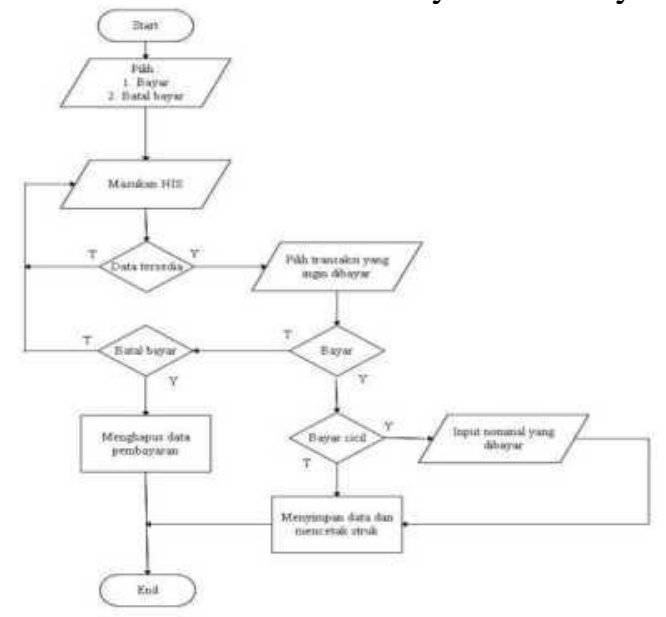

Gambar 11. Flowchart Tambah Pembayaran Lainnya

i. Flowchart Tambah Pembayaran SPP

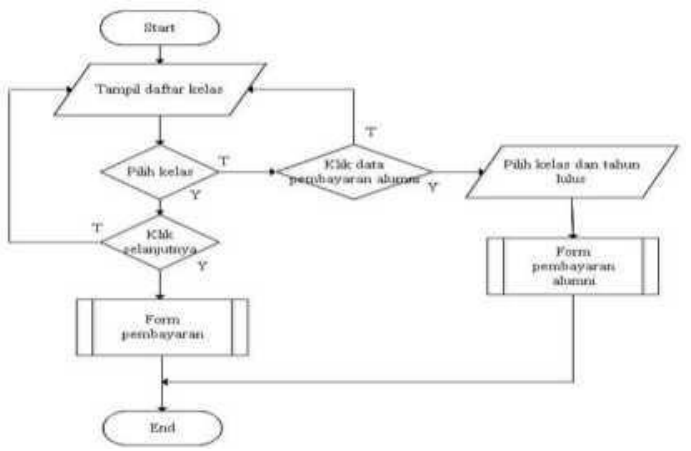

Gambar 12. Flowchart Tambah Pembayaran SPP j. Flowchart Pembayaran SPP Lanjutan

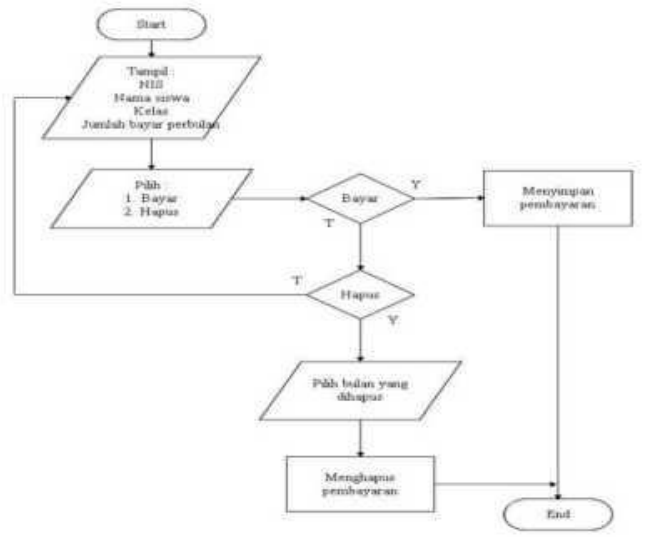

Gambar 13. Flowchart Pembayaran SPP Lanjutan

k. Flowchart Pembayaran SPP Lanjutan

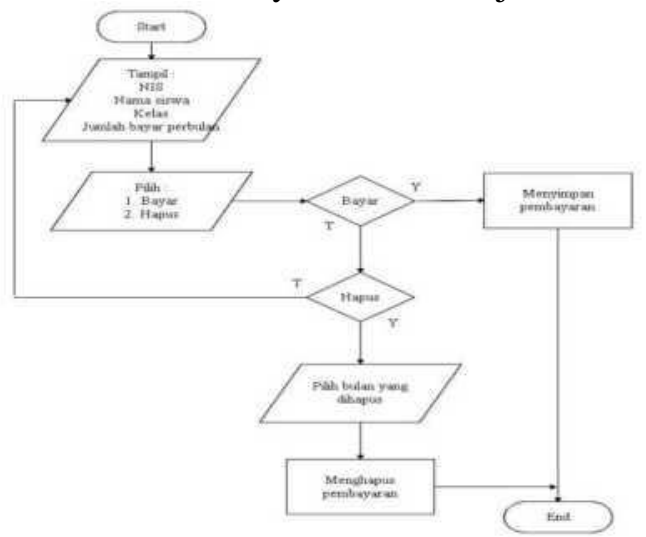

Gambar 14. Flowchart Pembayaran SPP Lanjutan

I. Flowchart Laporan Transaksi

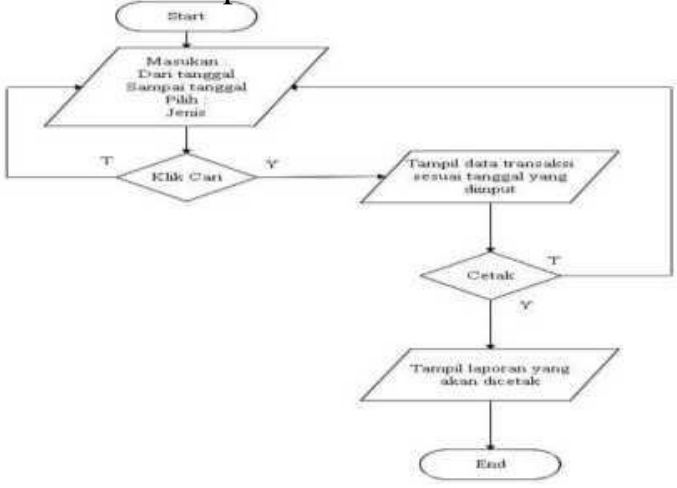

Gambar 15. Flowchart Laporan Transaksi 
m. Flowchart Laporan Status Pembayaran SPP

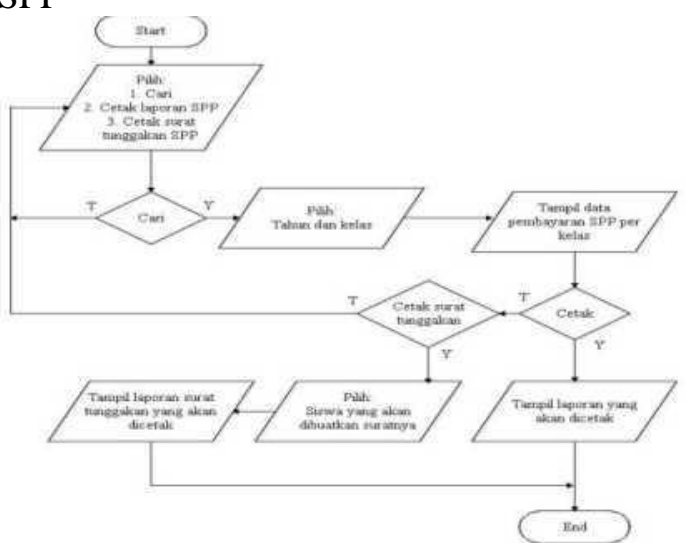

Gambar 16. Flowchart Laporan Status Pembayaran SPP

n. Flowchart Laporan Pembayaran Lainnya

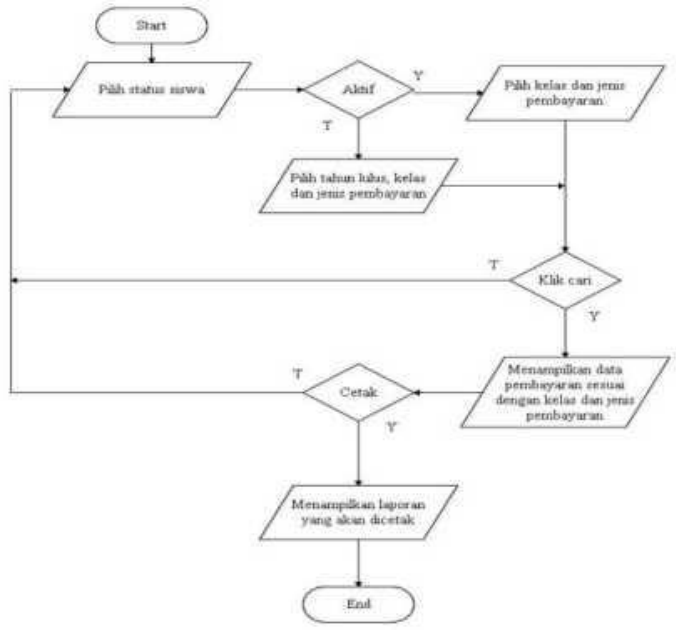

Gambar 17. Flowchart Laporan

Pembayaran Lainnya

\section{Pengkodean}

Di dalam penelitian penelitian ini, peneliti menggunakan macam-macam kode sebagai berikut:

a. Nama Kode : Kode Pembayaran SPP

Fungsi : Untuk mengetahuibulan dan siswa yang membayar

Panjang : : 11 digit

Tipe : Varchar

Format :

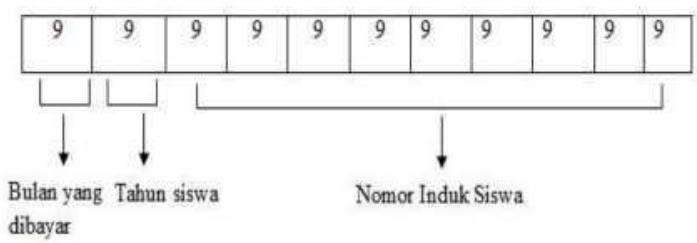

Contoh

\begin{tabular}{|l|l|l|l|l|l|l|l|l|l|l|}
\hline 5 & 2 & 1 & 8 & 1 & 9 & 1 & 0 & 0 & 0 & 8 \\
\hline
\end{tabular}

Keterangan 5 : Bulan Mei 2

: Tahun Ke-2

181910008 : Nomor induk siswa

b. Nama Kode : Kode Pembayaran Lain - lain Fungsi : Untuk mengetahui jenis pembayaran yang dilakukan dan siswa yang membayar

Panjang : 14 digit

Tipe : Varchar

Format :

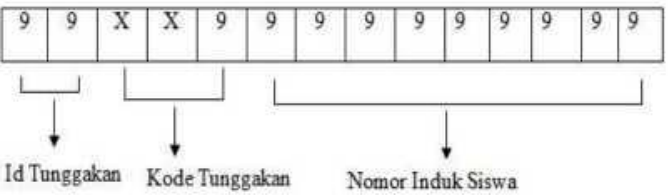

Keterangan 38 : ID Tunggakan

Contoh

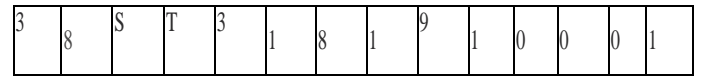

ST3 : Kode Tunggakan

181910008 : Nomor induk siswa

\section{Spesifikasi Sistem Komputer}

Untuk memperoleh kemampuan yang optimal dalam pengolahan data diperlukan aspek dasar yaitu perangkat keras dan perangkat lunak yang saling berkaitan satu dengan yang lainnya sehingga tidak dapat dipisahkan, karena suatu sistem komputerisasi tidak akan berjalan 
tanpa salah satu aspek tersebut. Perangkat lunak dan perangkat keras harus dapat menunjukan kerja yang baik dan sesuai dengan yang diharapkan.

a. Spesifikasi Perangkat Keras Minimum

Spesifikasi perangkat keras minimum yang diusulkan

sebagai

berikut :

Celeron

Standar

1. Processor 100GB

2. Keyboard 1GB DDR3

3. Hardisk Standar 10"

4. Ram

5. Mouse

6. Monitor b. Spesifikasi Perangkat Lunak Minimum

Bagian penting lain yang mendukung suatu program adalah perangkat lunak (software) yang digunakan dalam mengeksekusi program aplikasi serta sistem operasi yang akan digunakan untuk menjalankan program tersebut, Adapun perangkat lunak yang digunakan sebagai berikut :

1. Sistem Operasi Windows 7

2. Java Runtime Environment 8

3. XAMPP Version $5.6++$

\section{Tampilan Form Splash}

9. Implementasi
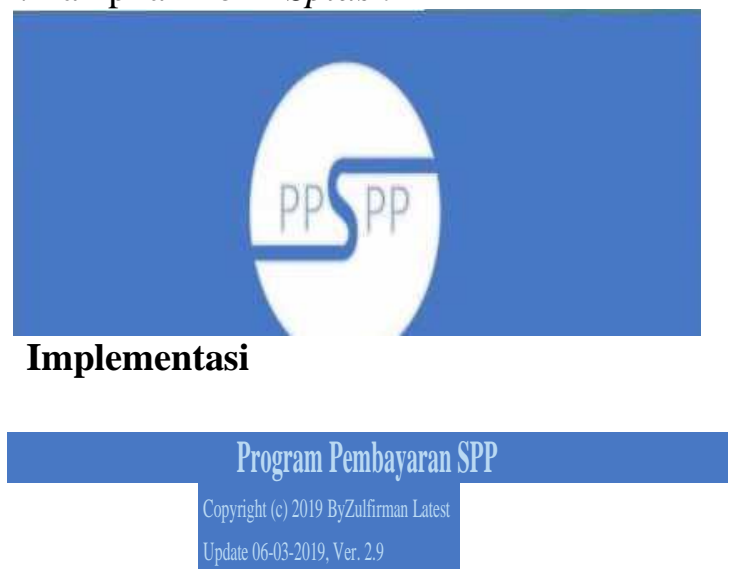

Gambar 18. Tampilan Form Splash

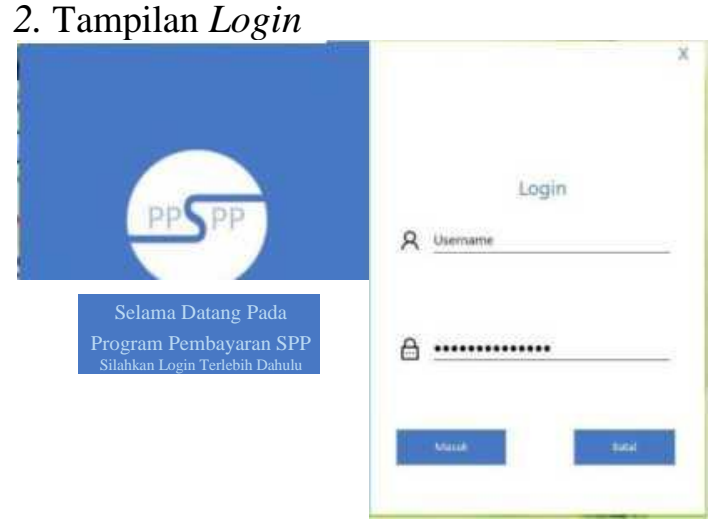

Gambar 19. Tampilan Login

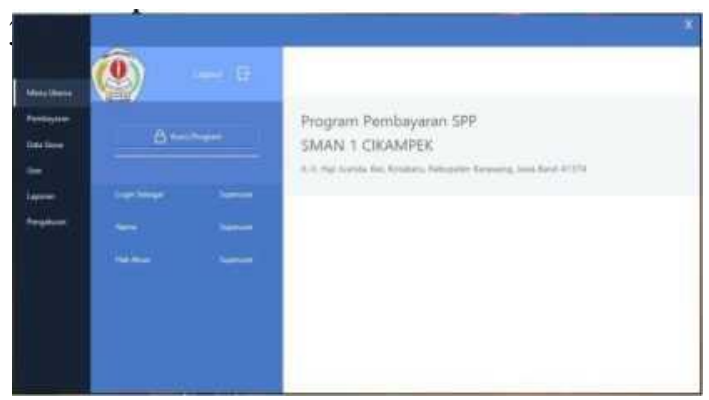

Gambar 20. Tampilan Menu Utama 4.

Tampilan Pembayaran

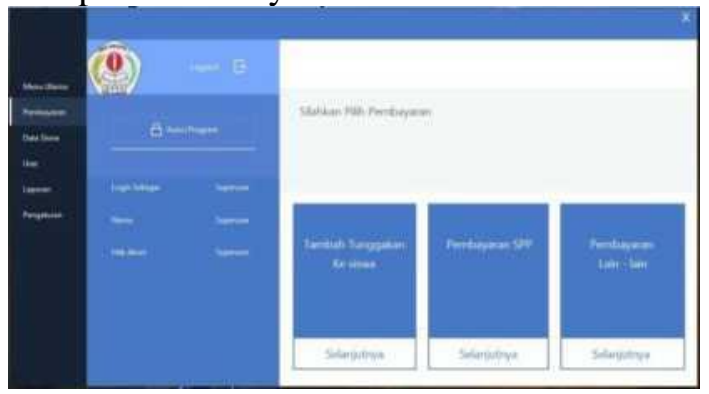

Gambar 21. Tampilan Pembayaran 5.

Tampilan Tambah Tunggakan

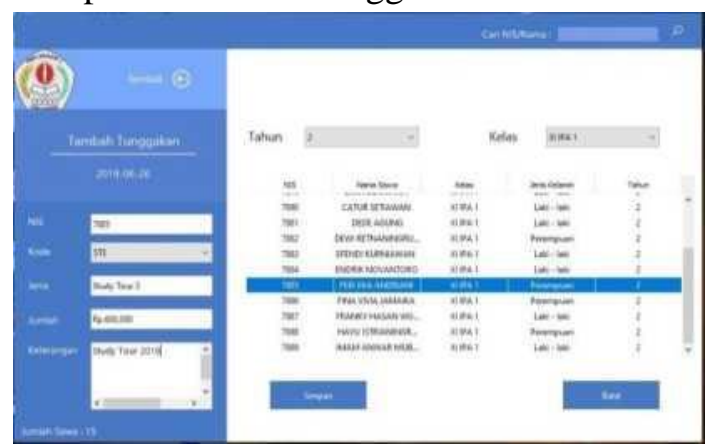

Gambar 22. Tampilan Tambah Tunggakan 
Tampilan Pembayaran SPP

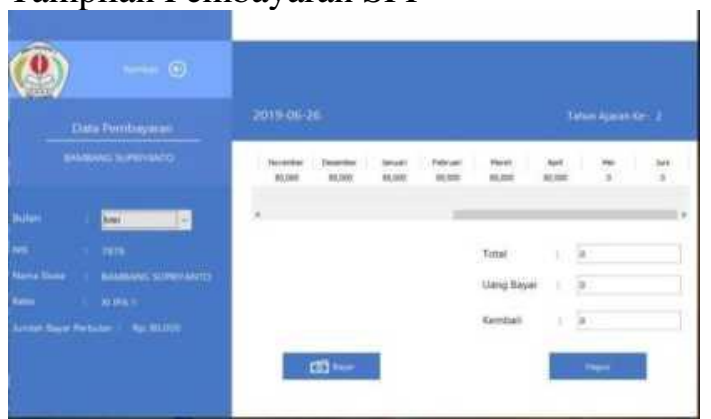

Gambar 23. Tampilan Pembayaran SPP

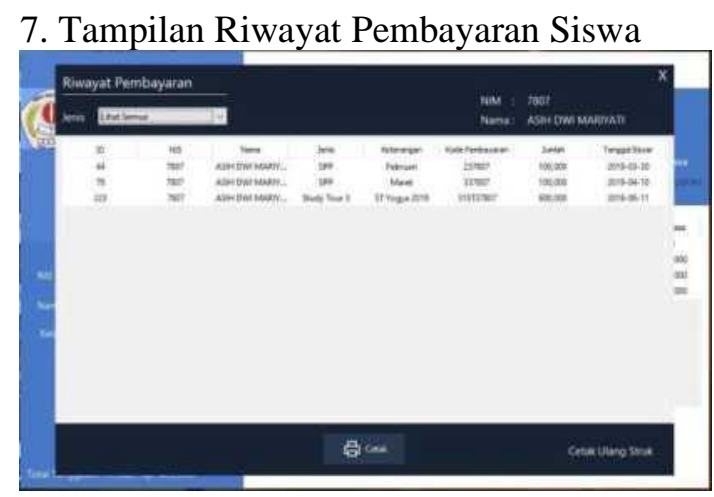

Gambar 24. Tampilan Riwayat Pembayaran Siswa

8. Tampilan Status Pembayaran SPP Siswa

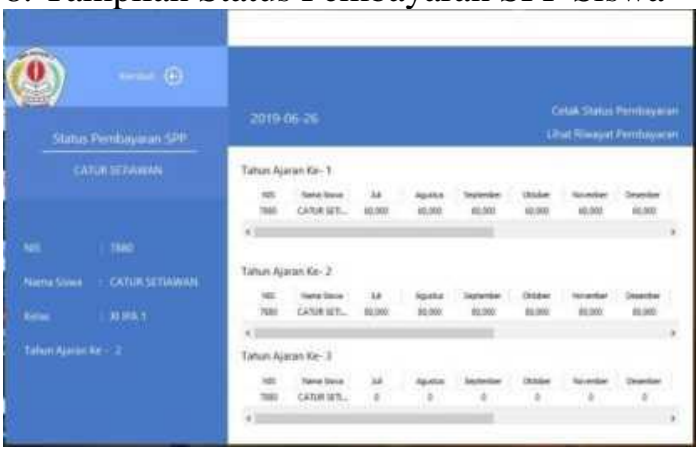

Gambar 25. Tampilan Status Pembayaran SPP Siswa

9. Tampilan Pembayaran Lainnya

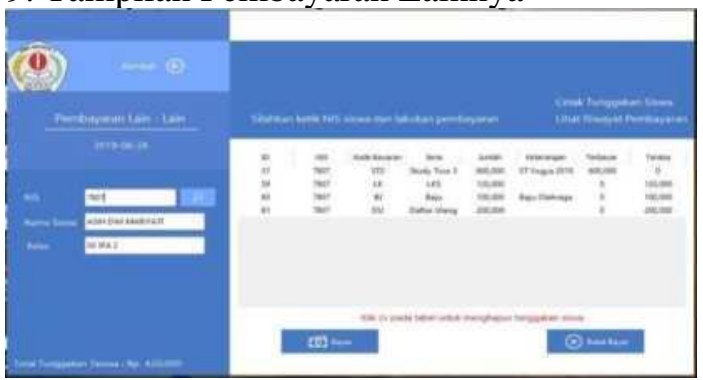

Gambar 26. Tampilan Pembayaran Lainnya
10. Tampilan Data Siswa

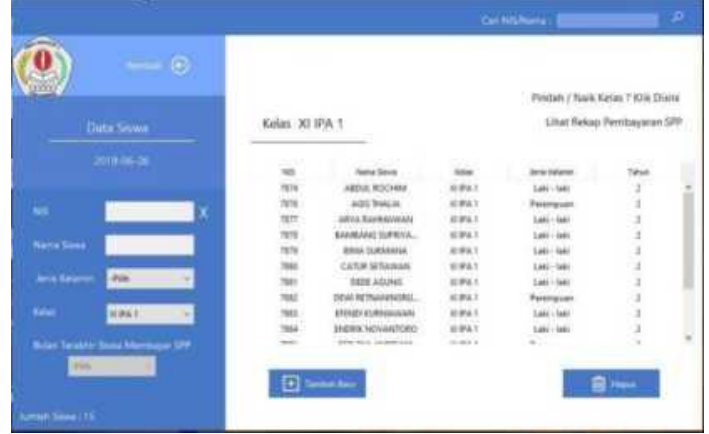

Gambar 27. Tampilan Data Siswa

\section{Tampilan Rekap Pembayaran SPP}

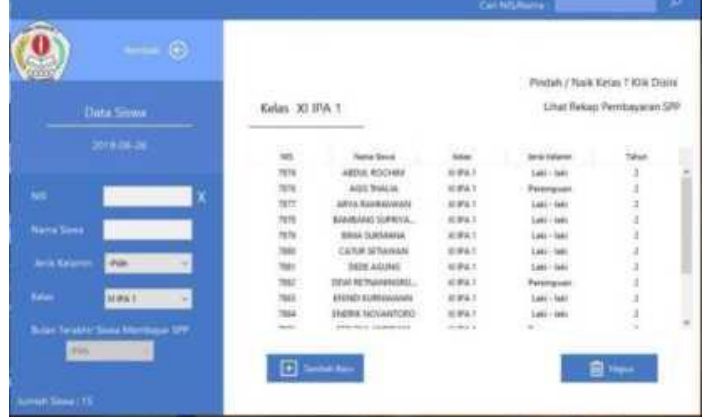

Gambar 28. Tampilan Rekap Pembayaran SPP 12. Tampilan Pindah atau Naik Kelas

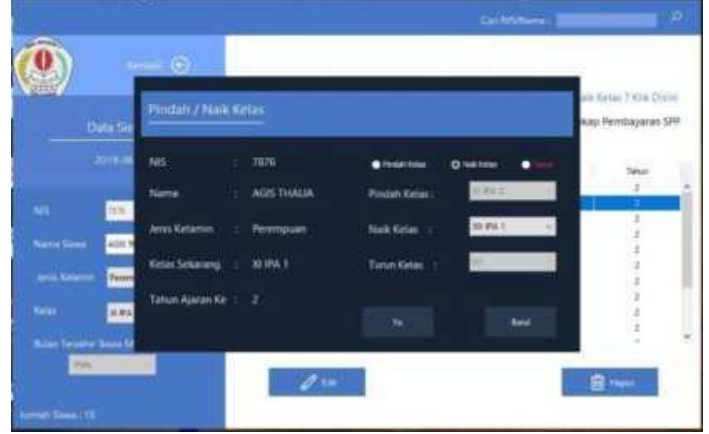

Gambar 29. Tampilan Pindah atau Naik

Kelas 13. Tampilan Pindah atau Naik Kelas

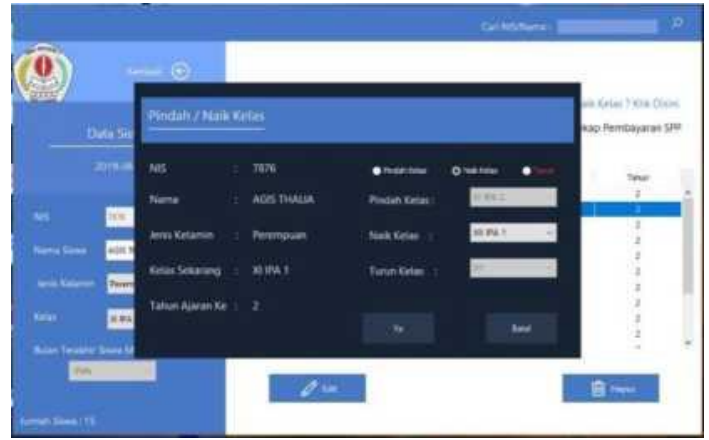

Gambar 29. Tampilan Pindah atau Naik Kelas

Jurnal Interkom: Jurnal Publikasi Ilmiah Bidang Teknologi Informasi dan Komunikasi

Volume 15 Nomor 02 Bulan Juli - Tahun 2020 
14. Tampilan Edit User

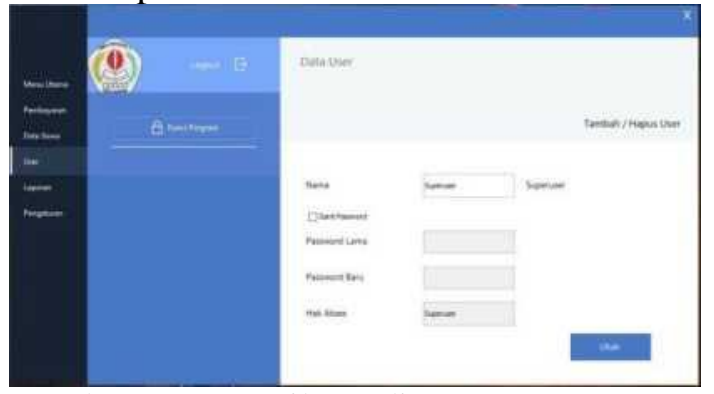

Gambar 30. Tampilan Edit User

15. Tampilan Tambah atau Hapus User

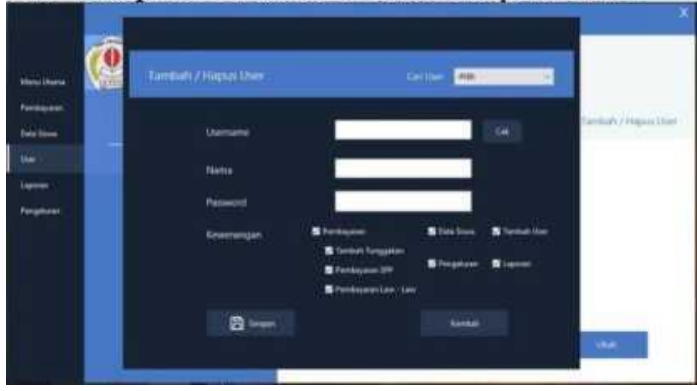

Gambar 31. Tampilan Tambah atau Hapus User

16. Tampilan Laporan Transaksi

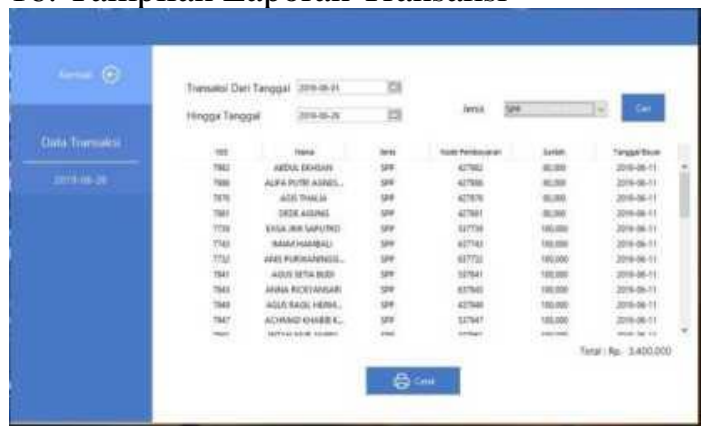

Gambar 32. Tampilan Laporan Transaksi 17.

Tampilan Status Pembayaran SPP

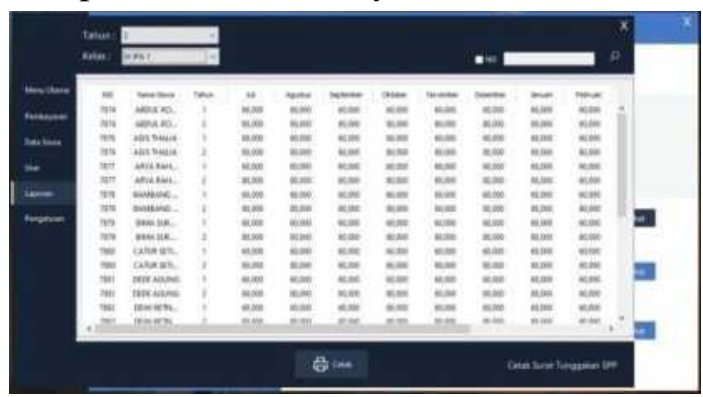

Gambar 33. Tampilan Status Pembayaran SPP

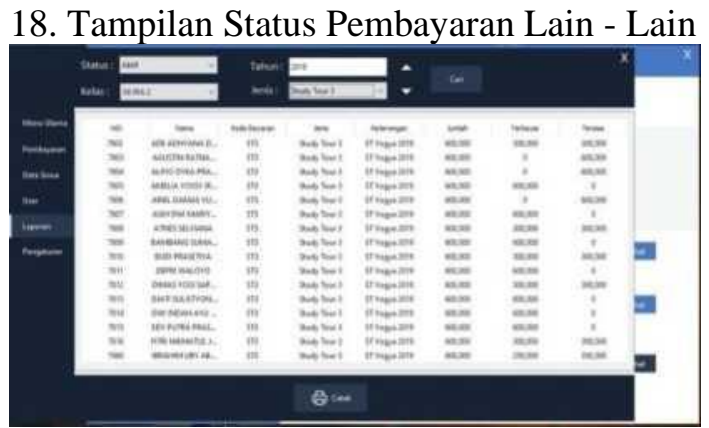

Gambar 34. Tampilan Status Pembayaran Lain - Lain

19. Tampilan Pengaturan

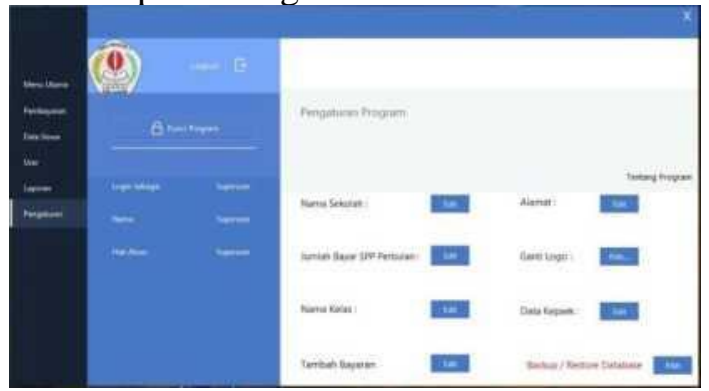

Gambar 35. Tampilan Pengaturan

\section{KESIMPULAN DAN SARAN}

\section{Kesimpulan}

Adanya program perpustakaan ini peneliti mengambil kesimpulan sebagai berikut:

1. Dengan adanya program yang dibuat ini dapat mempermudah bagian bendahara dalam mencatat pembayaran SPP, study tour, dan pembayaran bimbingan belajar.

2. Membantu bagian bendahara dalam membuat laporan bagi setiap pembayaran yang ada.

3. Mempermudah bagi kepala sekolah dan bendahara dalam melihat tagihan SPP, maupun tagihan pembayaran lainnya.

\section{Saran}

Dari kesimpulan diatas, peneliti memberikan saran-saran agar program 
aplikasi administrasi pembayaran sekolah dapat [8] berjalan secara optimal. Adapun saran-saran dari peneliti adalah:

1. Diadakannya perawatan (maintenance) terhadap hardware maupun software secara berkala.

2. Diharapkannya ada komputer khusus untuk guru dan hak akses untuk guru, agar guru bisa membuat tagihan dan melihat tagihan tagihan siswa yang berkaitan dengan guru tersebut.

\section{DAFTAR PUSTAKA}

[1] M. S. Azis, "Pelatihan Pembuatan Laporan Rekapitulasi Keluarga Prasejahtera Pada Kecamatan Karawang Barat," J. Abdimas BSIJ. Pengabdi. Kpd. Masy., vol. 2, no. 2, pp. 295-305, 2019.

[2] M. Rahman, Ilmu Administrasi. Makassar: Sah Media, 2017.

[3] S. Ayumida, "Aplikasi TASIBAR (Pendaftaran Siswa Baru) pada SD Negeri Cikampek Selatan I- Karawang," J. Interkom Vol. 13 No. 2, vol. 13, no. 2, pp. 21-30, 2018.

[4] F. Natalia, S. Ayumida, and L. A. Safitri, "Rancang Bangun Sistem Informasi Akuntansi Pembayaran Hutang atas Pembelian Obat Pada Apotek Nur Mulia Farma," Syntax J. Inform., vol. 8, no. 2, p. 110, 2019.

[5] R. Yanto, Manajemen Basis Data Menggunakan MySQL. Yogyakarta: Budi Utama, 2016.

[6] S. Ayumida, M. Tabrani, F. Natalia, and K. A. Hariri, "Aplikasi Propas (Program Pengarsipan Surat) Pada Kantor Desa Cihambulu-Subang," J. Interkom, vol. 14, no. 3, pp. 4-11, 2019.

[7] G. Rahmayanti, R. Sopandi, M. S. Aziz, and M. Qomaruddin, "Rancang Bangun Aplikasi Perpustakaan pada SMP Negeri 1 Ciasem Subang," J.

Interkom, vol. 13, no. 3, pp. 4-13, 2018.
A. Maulana and Y. K. Suhada, "Perancangan Aplikasi Repository Intranet Pada Laboratorium Komputer Kampus A STMIK Rosma," Infoman's, vol. 12, no. 1, pp. 14-24, 2018. 